\title{
Neuroendocrine Tumor of Larynx: A case report
}

\author{
Deepak Paudel, Amod Shrestha, Shyam Thapa Chettri, Bajrang Prasad Sah, Paricha Upadhyaya ${ }^{2}$ \\ ${ }^{1}$ Department of ENT and Head and Neck Surgery, ${ }^{2}$ Department of Pathology, B.P. Koirala Institute of Health Sciences, \\ Dharan, Nepal.
}

\begin{abstract}
Neuroendocrine neoplasms of the larynx are rare but are the second most common tumors of the region. It is difficult disease to diagnose due to clinical and pathological heterogeneity of the condition. We report a 50 year old non-smoker lady with neuroendocrine tumor of supraglottic region of the larynx who was managed with endoscopic excision of the tumor and had no recurrence till 2 years of follow up.
\end{abstract}

Keywords: head and neck; larynx; neuroendocrine tumor.

\begin{abstract}
INTRODUCTION
Any lesion in the larynx should be paid special attention and considered as squamous cell carcinoma until proven otherwise, neuroendocrine tumor of the larynx is a rare entity still it is the second most common tumor of the larynx. ${ }^{1}$ Extra pulmonary neuro-endocrine tumor (NET) is a relatively rare disease and larynx is the commonest site in head and neck region. NET consists of $0.5-$ $1 \%$ of epithelial carcinoma of larynx, arytenoid, aryepiglottic fold and epiglottis are the usual site. ${ }^{2,3}$ Neuro-endocrine tumor mainly affect males, female to male ratio is $1: 3$ and smoking is the proven risk factor. $^{2} \mathrm{We}$ report a case of laryngeal neuroendocrine tumor on a 50 year old non-smoker lady which was managed with endoscopic excision of the mass.
\end{abstract}

\section{CASE REPORT}

A fifty years old non-smoker female presented with pain in the throat, hoarseness, difficulty in swallowing initially for solid food and later for solid and liquid both since last five months. She was not known case of diabetes mellitus, hypertension, pulmonary tuberculosis and head and malignancy. Flexible laryngoscopy revealed pinkish cystic mass attached to the laryngeal and lingual surface of right side of epiglottis, right arytenoid and aryepiglottic fold and both the vocal cords were mobile (Figure 1). Contrast enhanced CT scan of the neck showed hypo dense mass in right side of the supraglottic region and it was not involving thyroid cartilage and vocal cord (Figure 2). Complete endoscopic removal of the mass was done under general anesthesia (Figure 3). Post-operative histopathology report showed neuroendocrine tumor (Figure 4) and advised for immunohistochemistry. Immunohistochemistry confirmed neuroendocrine tumor grade II and

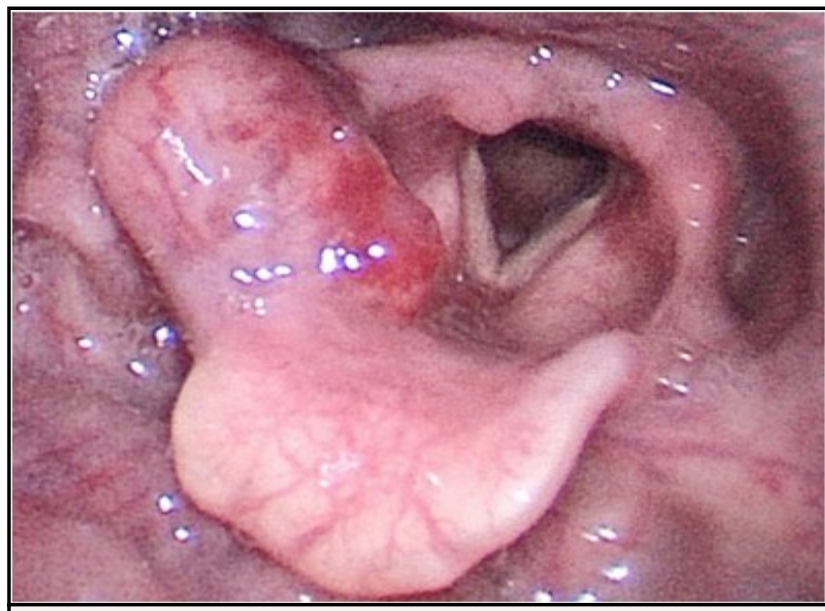

Figure 1. Pre-operative laryngoscopy image.

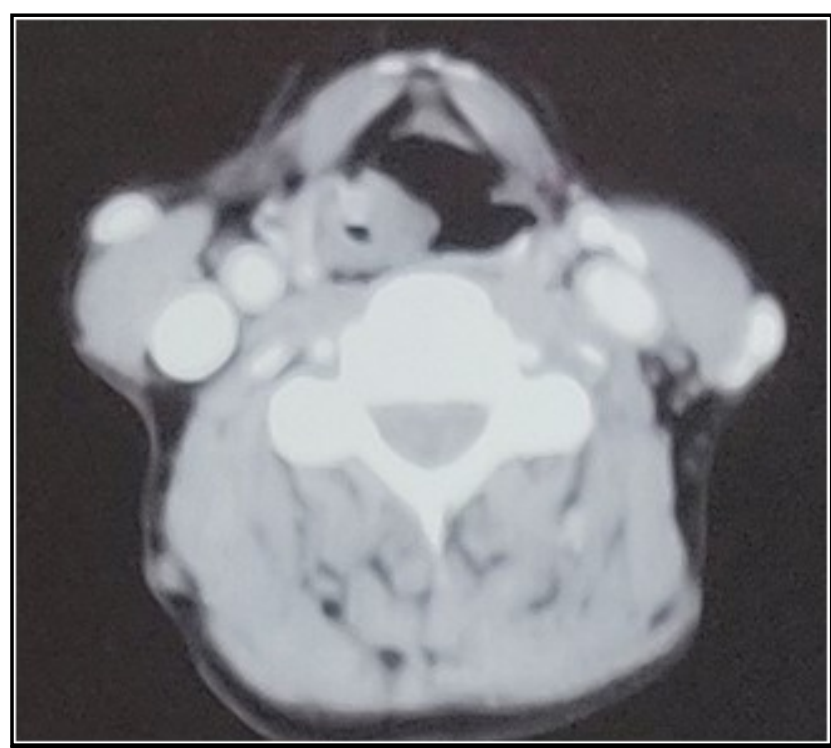

Figure 2. CECT Neck: Hypodense lesion in right supraglottic larynx.

Correspondence: Dr. Deepak Paudel, Department of ENT and Head and Neck Surgery, B.P. Koirala Institute of Health Sciences, Dharan, Nepal. Email: deepakpaudel339@gmail.com. Phone: +977-9842029611. Article received: 2020-01-06. Article accepted: 2020-03-13. 
Paudel et al. Neuroendocrine Tumor of Larynx: A case report.
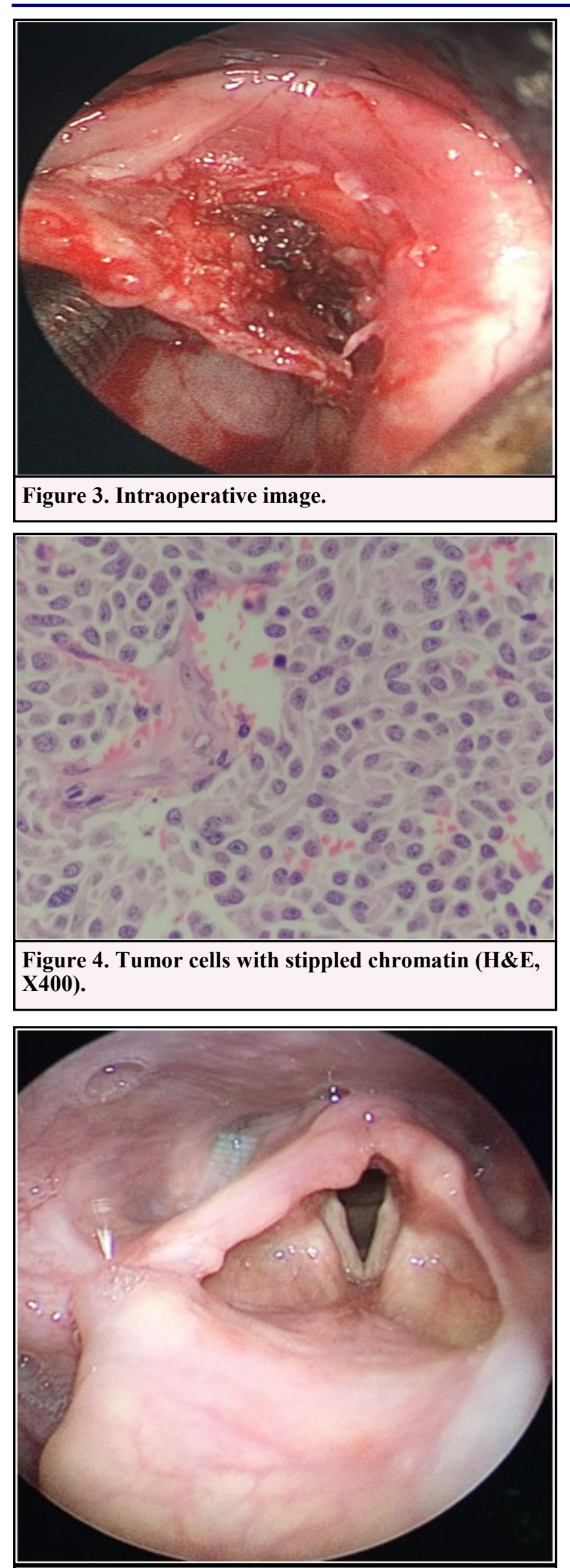

Figure 5. Laryngoscopy image after 2 years. adjuvant therapy was not required. Circulating levels vanillylmandelic acid and 5-hydroxyindole acetic acid (5-HIAA) were within the normal limits. Patient is in regular follow up since last 2 years and has normal voice, no features of dysphagia and flexible laryngoscopy revealed no recurrence of lesion (Figure 5).

\section{DISCUSSION}

Neuro-endocrine tumor most commonly arises in the gastrointestinal or respiratory systems and rarely arises in the head and neck region. Larynx is the commonest site of neuroendocrine tumor in head neck region and it is the most common non-epidermoid laryngeal carcinoma and consists of 0.5 to $1 \%$ of all epithelial cancer and mostly occurs in supraglottic region. ${ }^{4}$ Neuroendocrine tumor are divided in to neural and epithelial based on the tissue of origin. Epithelial category consists of 3 types: typical carcinoid (well differentiated neuroendocrine carcinoma, grade I), atypical carcinoid (moderately differentiated neuroendocrine carcinoma, grade II; large cell neuroendocrine carcinoma) and small cell neuroendocrine carcinoma (poorly differentiated neuroendocrine carcinoma, grade III). Neural category consists of paraganglioma. ${ }^{5}$

They are more common in male and common age of presentation ranges from 50 to 70 years and about two third of them are smoker.6 No clinical symptoms are characteristics of the condition and depends upon the site and extent of the disease. The most common symptoms are hoarseness, dysphagia, odynophagia, dyspnea and hemoptysis. ${ }^{2}$ Neuroendocrine tumors are associated with paraneoplastic syndrome and such association should be thoroughly investigated as it changes the management plan. The possible symptoms of paraneoplastic syndrome are headache, confusion, hyponatremia, reduced hematocrit level. Syndrome of inappropriate secretion of antidiuretic hormone (SIADH), myasthenia syndrome, ectopic adrenocorticotropic hormone (ACTH) syndrome are some of the described condition. ${ }^{5}$

Diagnosis of the condition may be delayed as it is a rare condition and diagnosis is made based on the findings of histopathology and immunohistochemistry. Presence of neuroendocrine morphology on light microscopy such as peripheral palisading of tumor nests, trabeculae, glandular differentiation, rosette formation, crush artifacts should be considered as NET. Subtype of NET is distinguished by immunohistochemistry. ${ }^{2}$ Surgical excision is the main stay of treatment, conservative surgery like endoscopic excision, supraglottic laryngectomy are preferred option but larger lesion may require total laryngectomy and neck dissection is usually not 
Paudel et al. Neuroendocrine Tumor of Larynx: A case report.

indicated. ${ }^{3,7}$ Our patient was treated with endoscopic excision of the lesion without neck dissection, and function of the larynx is preserved. Radiotherapy and chemotherapy are reserved for unfavorable histology and somatostatin analogues can be considered in patients with inoperable or metastatic disease to slow down growth and control carcinoid syndrome. ${ }^{8}$ Prognosis of grade I and Grade II neuroendocrine tumor has average prognosis with 5 year overall survival of $48 \%$ and 10 year survival rate of $30 \%$ but poorly differentiated NETs (grade III) or NETs with a high proliferation index had poor prognosis and $10 \%$ of 5 year of median survival. ${ }^{8}$

\section{CONCLUSIONS}

Neuro endocrine tumor of the larynx is a rare still a second most common tumor in this region. Diagnosis is often delayed due to heterogeneity of the clinical and pathological features. Association with paraneoplastic syndrome should be thoroughly investigated though association is rare and managed accordingly. Surgery is the main stay of treatment and other modalities of treatment are reserved for patient with advance disease and poorer histology.

\section{Conflict of Interest: None}

overview. Head Neck. 2009;31(12):1634-46.

\section{REFERENCES}

1. Zhu Y, Gao L, Meng Y, Diao W, Zhu X, Li G, et al. Laryngeal Neuroendocrine Carcinomas: A Retrospective Study of 14 Cases [Internet]. BioMed Research International. 2015 [cited 2020 Jan 1]. Available from: https:// www.hindawi.com/journals/bmri/2015/832194/ cta/

2. Procopio G, Ricotta R, Fusi A, Celio L, De Dosso S, Catena L, et al. Neuroendocrine Tumors of the Larynx: A Clinical Report and Literature Review. Tumori J. 2006 Jan 1;92 (1):72-5.

3. Jaiswal VR, Hoang MP. Primary Combined Squamous and Small Cell Carcinoma of the Larynx: A Case Report and Review of the Literature. Arch Pathol Lab Med. 2004 Nov 1;128(11):1279-82.

4. Ferlito A, Silver CE, Bradford CR, Rinaldo A. Neuroendocrine neoplasms of the larynx: An
5. Carić T, Bilić M, Kovač Bilić L, Prgomet D, Kovačić J, Topić Grahovac I, et al. Neuroendocrine Tumors of Larynx - Two Case Reports and Literature Review. Coll Antropol. 2012;36 supplement 2(2):173-8.

6. Machens A, Holzhausen H-J, Dralle H. Minimally invasive surgery for recurrent neuroendocrine carcinoma of the supraglottic larynx. Eur Arch Otorhinolaryngol. 1999 May 1;256(5):242-6.

7. Perez-Ordoñez B. Neuroendocrine Carcinomas of the Larynx and Head and Neck: Challenges in Classification and Grading. Head Neck Pathol. 2018 Mar 1;12(1):1-8.

8. Ferrarotto R, Testa L, Riechelmann RP, Sahade M, Siqueira LT, Costa FP, et al. Combination of Capecitabine and Oxaliplatin is an Effective Treatment Option for Advanced Neuroendocrine Tumors. Rare Tumors. 2013 Jul 17;5(3):121-5.

Citation: Paudel D, Shrestha A, Chettri ST, Sah BP, Upadhyaya P. Neuroendocrine Tumor of Larynx: A case report. JCMS Nepal. 2020; 16(1):54-6. 